Filo. y Lingüí. 10(2): 3-13, 1984.

\title{
REFLEXIONES ACERCA DE LA POLEMICA SOBRE NACIONALISMO LITERARIO
}

Alvaro Quesada Soto

\section{El inicio de la polémica}

A pesar de ligeras discrepancias en algunos detalles, todos los historiadores de nuestra literatura coinciden en señalar cómo, entre los años 1890 y 1900 , surgen una serie de fenómenos culturales y literarios, que nos permiten considerar esta década como aquella en la que las esporádicas manifestaciones literarias anteriores cristalizan y maduran, para producir lo que podríamos llamar el inicio de una literatura consciente de sí misma. En esta época se lleva a cabo la publicación de las primeras obras en que la intención $-y$ en algunos casos el valor literario- desborda los límites de la crónica o el cuadro de costumbres; se establecen grupos o tendencias definidas, y se inicia la discusión teórica incipiente entre ellos.

A partir de la publicación en 1890 de La lira costarricense, primera recopilación de poesía nacional editada por Máximo Fernández, y la aparición en 1894 de nuestro primer libro de cuentos, Hojarasca, de Ricardo Fernández Guardia, surgen, en ios linderos del siglo, una serie de narradores con un estilo, conocimiento y manejo de recursos y temas, propios y originales, que les da el derecho a ser considerados nuestros primeros clásicos. Descuellan entre esos autores los nombres de Ricardo Fernández Guardia, Carlos Gagini, Manuel González Zeledón (Magón), Aquileo J. Echeverría y Joaquín García Monge.

La publicación de Hojarasca de Fernández Guardia en 1894, suscitó una carta de Antonio Zambrana y un artículo crítico de Carlos Gagini; así se inicia una polémica que bien puede ser considerada la primera discusión teórica sobre literatura en nuestra historia. "Desde 1894 y en un período que se prolongó hasta los primeros años del siglo $\mathrm{XX}$, se planteó el conflicto entre el nativismo o sea el propósito de crear una temática autóctona y el exotismo o sea la imitación de la literatura extranjera, especialmente la francesa" (1). A lo largo de más de una década, en diversas revistas y periódicos, escritores e intelectuales de muy variada filiación, se cuestionaron y dieron sus respuestas a problemas trascendentales de nuestra li- teratura: ¿cómo debemos escribir?, ¿cómo debe ser la literatura costarricense?, ¿cuáles han de ser los temas y personajes y cuál el lenguaje y la manera apropiada de enfrentarlos?

La polémica dio lugar a distintas respuestas que encerraban a su vez actitudes muy diversas hacia la literatura y la realidad. "De un lado están los que sufren el influjo de 'la ciudad de las luces' y creen de buen tono usar galicismos y citar a cada paso autores franceses para demostrar su cultura. Del otro lado están los que se burlan de 'la turbamulta de aficionados al decadentismo que entre nosotros hace furor' " (2). Dos polos opuestos quedaron claramente demarcados desde un principio, en los artículos de Carlos Gagini y Ricardo Fernández Guardia, que dieron inicio a la polémica.

En una nota crítica a Hojarasca, publicada en mayo de 1894 con el seudónimo Amer, Gagini se quejaba de que mientras "se recurre a argumentos gastados, se pintan escenas y se trazan diálogos que lo mismo pueden desarrollarse aquí que en Madrid o París... nadie se ocupa de estudiar nuestro pueblo y sus costumbres desde el punto de vista artístico, nadie piensa en desentrañar los tesoros de belleza encerrados en los dramas de nuestras ciudades $y$ en los idilios de las aldeas, en la vida patriarcal de nuestros antepasados, y en lo recóndito de las almas y en la naturaleza exuberante que despliega ante nuestros ojos indiferentes su grandiosa poesía" (3).

Fernández Guardia contestó a Gagini:

"El país que después de muchos siglos de existencia y prosperidad logra tener arte y literatura nacionales, ha llegado a la más alta cima de su civilización, y así se dice el arte griego, el arte romano, la literatura francesa, las letras españolas. Y icuándo le parece a usted que podría decirse el arte o la literatura costarricenses? Yo, Dios me lo perdone, me imagino que nunca... Por lo que hace a mí, declaro ingenuamente que el tal nacionalismo no me atrae poco ni mucho. Mi humilde opinión es que nuestro pueblo es sandio, sin gracia alguna, desprovisto de toda poesía y originalidad que puedan dar nacimiento siquiera a una pobre sensación artística... Se comprende sin esfuerzo que con una griega de la antigüedad, dotada de esa hermosura expléndida y severa que ya no existe, se pudiera hacer una Venus de Milo. De una parisiense graciosa y delicada pudo nacer la Diana de Houdon; pero, vive Dios que con una 
india de Pacaca sólo se puede hacer otra india de Pacaca" (4).

Benjamín de Céspedes terció en la polémica con un interesante artículo en que critica, con ejemplos de la gran literatura de su época, la falsa oposición nacional-universal en que basaba sus argumentos Fernández. El artículo de Céspedes Ilama la atención además porque demuestra un amplio conocimiento -insospechado en nuestro reducido medio cultural finisecular- no sólo de los grandes maestros, sino también de autores rusos y escandinavos menos conocidos:

\begin{abstract}
"El señor Fernández cree que no podrá haber arte ni literatura costarricense por la carencia de asuntos bellos en un país esencialmente infeliz y prosaico. Quisiera yo conocer la gracia, el talento, la belleza, la poesía del pueblo ruso, desaseado, soez, supersticioso, servil, brutal, ebrio; y sin embargo hay allí hombres... que se han inspirado con felicísimo arte realista en las desgracias de su nación; escritores de la talla de Herzen, Ogaref, Tourgueneff, Schtchedryne, Dostoyevski, Gogol, Tolstoi y otros que han hecho sacar al sol toda esa podredumbre, purificada por medio del arte (...)" (5).
\end{abstract}

Finalmente sostenía Céspedes que el escritor "como el pescador de perlas", se sumerge en la realidad, "busca, lucha, remueve el légamo, logra romper el banco calizo de madréporas"; y cuando "sube al fin a la superficie con la codiciada presa, unos encuentran entre las valvas la hermosa perla, otros... sólo pescan la ostra huera, los ratés de la literatura, que no hallan sino perlas de vidrio de patente francesa o española" (6).

Un análisis detallado del concepto de literatura -explícito o implícito- en los textos, críticos y literarios, de algunos participantes en la polémica, nos llevará a sacar interesantes conclusiones acerca de importantes aspectos, hasta ahora a nuestro entender inéditos en nuestra historia y crítica literaria.

\section{Gagini y Fernández Guardia: divergencia y coincidencia.}

Los historiadores de nuestra literatura han insistido tradicionalmente en que la polémica sobre nacionalismo se centró alrededor del problema del lenguaje. Abelardo Bonilla aseguraba que "la polémica se planteó... no concretamente sobre las posibilidades del nacionalismo en lo referente a los temas, sino sobre la conveniencia o inconveniencia... de un lenguaje directo y realista, copia fiel del habla del campesino" (7). Y Alfonso Chase aseguraba que "el problema de fondo, era muy sim- ple: ¿Se podía describir lo nuestro con un lenguaje literario, aceptable, valioso, rico?. Esa es la tesis cardinal de Carlos Gagini... Era la eterna lucha entre el Diccionario de la Academia Española y el de "Costarriqueñismos"... entre las formas de expresión nacional, barbarismos para los puristas, y el lenguaje español, bendecido por la Academia..." (8). Pero estas afirmaciones, como veremos, sólo son válidas con respecto al desarrollo ulterior de la polémica; no a sus inicios.

Los textos anteriormente citados de Gagini, Fernández y Céspedes permiten afirmar que la polémica, al menos en sus inicios, se centró - al contrario de lo aseverado por Bonilla y Chase- sobre la temática y el contenido, sin referencia al lenguaje. Lo que se discute en estos primeros artículos es si la vida costarricense - "nuestro pueblo y sus costumbres", "los dramas de nuestras ciudades", "Ios idilios de nuestras aldeas", "la vida patriarcal de nuestros antepasados" y la "naturaleza exuberante", pueden ser fuente de "poesía" y objeto de tratamiento "artístico".

Creemos que es precisamente esta referencia exclusiva al contenido, la debilidad fundamental del planteamiento dado en sus inicios por Gagini y Fernández Guardia a la polémica. Pues a pesar de la aparente oposición entre las concepciones de estos dos autores, pensamos que ambos partieron de una base común, implícita en su teoría y en su práctica literaria. A pesar de su oposición en cuanto a la temática y a los asuntos que podían ser tratados de manera literaria; su opinión sobre la manera literaria -ciertos elementos formales y lingüísticos válidos para enfocar cualquier temaparece ser coincidente. Ambos suponen que "el punto de vista artístico", o sea la forma literaria, es independiente y autónoma de la realidad, y que puede ser aplicada indiscriminadamente, como un patrón abstracto de validez universal, a cualquier contenido. $Y$ ambos consideran que ese patrón o modelo abstracto, es el criterio sobre el valor artístico y las leyes sobre género, recursos y lenguaje, canonizados por la teoría y las prácticas literarias europeas, españolas o francesas.

De aquí que -como bien lo han señalado varios críticos (9) - a pesar del nacionalismo temático de Gagini, sus cuentos publicados en Chamarasca (1898) no impliquen, con respecto a Hojarasca, una ruptura en cuanto a la tradición literaria académica, ni una innovación en la búsqueda de una literatura auténticamente nacional, que represente un avance en la indagación de la realidad, el espíritu y el hombre costarricenses. 
En realidad el descubrimiento de un auténtico "punto de vista artístico" en nuestra literatura, implicaba la creación de una unidad dialéctica apropiada, que lograra reunir, tanto los contenidos y temas, como los elementos formales, necesarios para una auténtica representación de la realidad costarricense, con sus características y peculiaridades propias (10). A este hecho hizo referencia -a su manera- Leonidas Briceño cuando intervino en 1900 en la polémica: "Nuestra naturaleza - aseguraba - nos habla de distinto modo que la de Iberia a los españoles; hay ecos en nuestras selvas y espectáculos en nuestras montañas que para designarlos tenemos que inventar palabras y ponerlos de relieve recurriendo a términos nuestros" (11). Lo mismo que Briceño señala con respecto a la naturaleza se podría aplicar también a la realidad social. Era necesario encontrar el género, la temática, el estilo y el lenguaje adecuados para representar literariamente los diversos y contradictorios aspectos de la vida social costarricense.

Esa es, creemos, la búsqueda que inician Magón y Aquileo, a su modo; Manuel de Jesús Jiménez y Ricardo Fernández Guardia (después de 1901), a su manera; y cuya síntesis intentará en sus obras Joaquín García Monge. Ellos logran una expresión literaria auténticamente nacional, al renunciar a la imitación desubicada del cuento naturalista europeo, para crear, mediante la introducción en la literatura "culta" y "artística" de elementos marginales, populares y extraliterarios, dos géneros criollos: el costumbrismo y la crónica histórica.

\section{La "canonización de los géneros inferiores"}

Sucede aquí un fenómeno que los formalistas rusos habían estudiado profusamente, y que ellos Ilamaron la "canonización de los géneros inferiores" (kanonizatsia nishij zhanrov) (12).

Tomashevski lo resume de la siguiente manera: los grandes acontecimientos literarios nacen de la inclusión en la literatura "artística", de recursos típicos de géneros o formas literarias consideradas "no artísticas", "inferiores", "menores" o extraliterarias. Se trata generalmente de formas de expresión popular, "folklóricas", "carnavalescas", "vulgares", o bien formas de expresión oral o escrita que caerían fuera de los límites y cánones establecidos para el "arte literario" (13). Según Tynianov (14), el que un determinado hecho escrito o lingüístico pase a ser un hecho literario, y el que un hecho literario pase, de ocupar un lugar "marginal" o "periférico", a ocupar un lu- gar "central"; depende de la función que cumpla dentro del sistema de la literatura en un determinado contexto histórico-literario. Fenómenos que dentro de las concepciones literarias de una época o un país no se consideran aptos para desempeñar funciones "artísticas" o "literarias", pueden llegar a desempeñarlas en otro contexto histórico-literario. $Y$ viceversa, las concepciones y los rasgos literarios que una época o país considera fundamentales y establecidos, pueden dejar de cumplir funciones literarias y perder su valor y vigencia al enfrentarse a nuevas circunstancias históricas. "Cuando en una época decae un género, éste pasa del centro a la periferia, y en su lugar de lo menudo, de los traspatios y bajos fondos de la literatura, surgen nuevos fenómenos que pasan a ocupar el centro" (15).

Roberto Fernández Retamar observó ya la utilidad de las anteriores concepciones aplicadas al estudio de la literatura hispanoamericana, en la que el fenómeno - tan estudiado por los formalistas rusos- de la "hibridez" (smeshenie) en los fenómenos literarios, es especialmente común y característico.

"...La línea central de nuestra literatura parece ser la amulatada, la híbrida, la "ancilar"; y la línea marginal vendría a ser la purista, la estrictamente (estrechamente) "literaria". Y ello por una razón clara: dado el carácter dependiente, precario de nuestro ámbito histórico, a la literatura le han solido incumbir funciones que en las grandes metrópolis le han sido segregadas ya a aquella. De ahí que quienes, entre nosotros, calcan o trasladan estructuras $y$ tareas de las literaturas en las metrópolis -como es lo habitual en el colonizado-, no suelen funcionar eficazmente, $y$ en consecuencia producen por lo general obra defectuosa o nula, pastiches intrascendentes; mientras quienes no rechazan la hibridez a que los empujan las funciones requeridas, son quienes suelen realizarse como escritores realmente creadores" (16).

Esto obliga a reconocer "el predominio en nuestras letras de géneros considerados 'ancilares' ": crónicas, artículos, memorias, formas sociográficas como el Facundo. "Al lado de ellos han solido empalidecer los otros géneros supuestamente centrales, en nuestro caso obviamente laterales..." (17). Fernández Retamar concluye diciendo que "sólo la concreta encarnación histórica, y no el abordaje apriorístico, puede revelarnos las verdaderas características y funciones de un hecho literario. La estrofa complicada, de raíz culta en España, se vuelve popular en tierras americanas, mientras la estrofa más suelta, desarrollada por el pueblo español, pasa a ser de factura culta entre nosotros" (18). 
Un fenómeno semejante a los señalados anteriormente tiene lugar, creemos nosotros, en la literatura costarricense en los linderos del siglo. El intento "academicista" o "exotista" por trasplantar intactos a nuestras tierras los fenómenos literarios europeos, sólo produce frutos anémicos y artificiales; mientras que el injerto criollo de fenómenos "marginales", "inferiores" o extraliterarios, dentro de la literatura, produce los únicos géneros válidos y vigentes para la época y la realidad: el "género concho" -como despectivamente lo llamó Fernández Guardia- y la crónica histórica. Estos dos géneros provenían de fuentes que dentro de los cánones académicos tradicionales no tenían abolengo literario: el periodismo y la historia. Así nuestra literatura "clásica" participa de este fenómeno de la "hibridez"; nuestros primeros clásicos buscaron su inspiración en el reportaje o la crónica de tipo periodístico, folklórico, satírico o humorístico, como es el caso de Magón, Aquileo y algunos cuentos de Fernández Guardia; o en los documentos, los archivos y los recuerdos históricos, como es el caso de Manuel Argüello Mora, Manuel de Jesús Jiménez y las crónicas de Ricardo Fernández Guardia.

\section{Magón y el género costumbrista}

No se equivocaba, entonces, Magón cuando en una carta dirigida a Joaquín García Monge con motivo de la publicación de E/ Moto en 1900, afirmaba ser el "fundador del género", e "iniciador o descubridor de la veta" del costumbrismo literario; contraponiéndose a "los hijos del país de los encantos y de los cuentos de hadas... (que) cierran los ojos y esconden la mano para irse con su imaginación tropical a pintar escenas parisienses que nunca han visto y formar atroces ramos con flores arrancadas de un tratado elemental de botánica" (19). En otra carta de 1924 dirigida a José María Arce, Magón criticaba a los que consideraban que sus cuentos costumbristas no eran literatura porque "se salian de las reglas": "Por eso el señor Pacheco, que ve las cosas desde el Arco de la Estrella o desde Nôtre Dame, encuentra que mis cuentos no tienen literatura. Olvidó decir francesa porque, aunque le pese, yo sigo creyendo que la tienen tica, que justamente es lo que yo trataba cuando los escribí" (20).

Los cuadros de costumbres se publicaban en los periódicos costarricenses muchos años antes de que Magón publicara sus cuentos (21). Pero no tenían pretensiones literarias; era considerado un género "periodístico", con pretensiones humorísticas o moralizantes, sin valor estrictamente literario. Esto es probablemente lo que suponía Gagini cuando en 1894 afirmaba que "nadie se ocupa de estudiar nuestro pueblo y sus costumbres desde el punto de vista artístico". El consideraba, por lo tanto, que los cuadros de costumbres publicados hasta ese entonces trataban los temas nacionales desde otro punto de vista, un punto de vista presumiblemente "periodístico" o "humorístico", pero no "artístico" o "literario". Sus cuentos publicados en Chamarasca en 1898 refuerzan esa tesis, al introducir temas nacionales tratados según los cánones formales y lingüísticos europeos y académicos.

No se puede considerar por otra parte que Gagini desconociera el lenguaje popular; todo lo contrario, fue un pionero en su estudio, y había publicado ya, en 1892, la primera edición de su Diccionario de barbarismos y provincialismos de Costa Rica. El hecho de que no lo utilizara en sus obras literarias en 1898 -a pesar de su defensa de la temática nacionalista en 1894- confirma la tesis de que no lo consideraba material idóneo para la expresión artística. El mismo título de su Diccionario -que más tarde sería sustituido por Diccionario de costarriqueñismos- parecía sugerir, con los términos "barbarismos y provincialismos", la referencia a un fenómeno deforme y marginal, ajeno a los usos aceptables y normales. El propio Gagini pareció reconocerlo así, al afirmar en 1918 en las Advertencias preliminares a la segunda edición de su Diccionario: "Sale pues esta edición... bajo un plan menos empírico: en ella considero las divergencias de nuestro lenguaje con relación a la lengua madre, no como simples corruptelas, introducidas por el capricho o la ignorancia, sino como resultado natural de la evolución fonética y semántica a que están sujetos los idiomas vivos" (22). Con lo cual viene a confirmar que en la época en que concibió y publicó la primera edición del Diccionario - dos años antes del inicio de la polémica - consideraba los "barbarismos y provincialismos" del lenguaje popular costarricense, "corruptelas, introducidas por el capricho o la ignorancia" en el seno de la "lengua madre".

La innovación de Magón, aprovechada más tarde por Aquileo y García Monge, consiste entonces en haber tenido en cuenta las sugerencias hechas por Gagini y Zambrana en 1894, pero ampliándolas y completándolas. Magón no sólo incluye en la literatura "temas" y "asuntos" de la vida popular, sino que otorga dignidad literaria al lenguaje "con- 
cho" y al género costumbrista, relegados hasta entonces al limbo literario del periodismo humorístico o la expresión folklórica. Este es un hecho que supo ya captar José María Arce cuando afirmaba que "Magón, sin atenerse a modalidades precedentes, lleva a la literatura una forma de arte folklórico (...). Quería reivindicar para lo nuestro - pueblo, tierra, lengua - el derecho a entrar de lleno en la literatura" (23).

Con la conjunción de todos estos factores nace una verdadera literatura costarricense, un conjunto de temas y recursos literarios integrados coherentemente en un nuevo sistema, capaz de expresar una nueva concepción del mundo y de la realidad. A esto mismo se refería en 1900, en otra etapa de la polémica, Leonidas Briceño, cuando -en el lenguaje y la terminología de la época - afirma que "la poesía es general a todos los pueblos", por lo que "no importa el género de lo escrito ni su escuela (...). Hay que tomar en cuenta además que las reglas no las dictan en la Península y que éstas en algunos de sus detalles no pueden privar aqui en América. Nuestra naturaleza nos habla de distinto modo que la de Iberia a los españoles... para designar(la) tenemos que inventar palabras y poner(la) de relieve recurriendo a términos nuestros" (24). Los cuentos de Magón, creemos nosotros, fueron una primera expresión de ese hallazgo. En ese sentido nos parece significativo el hecho de que sólo después de aparecidos los primeros cuentos de Magón la polémica se planteó sobre sus verdaderas bases; abarcó, no solamente el aspecto temático, sino también los aspectos formales y lingü ísticos, tal como lo afirmaban -pero sin hacer referencia al cambio-Bonilla y Chase.

Ya en la segunda mitad de la década, lo que José María Arce llama "arremetidas cultistas" contra la nueva literatura costumbrista tomaba en cuenta ambos aspectos. Consideraban, según Arce, que el traslado de la realidad popular a la página literaria corre el riesgo de caer en lo pedestre y vulgar, en "halagar las pasiones del vulgo... dándole rienda suelta al sentimentalismo", o recurrir a la chabacanería en su afán de hacer reír. Alegaban por igual que el uso del idioma vernáculo implica un deterioro del lenguaje (25). De hecho, ya en 1896 -Magón había publicado para entonces sus 13 primeros cuentos- el propio Magón planteaba la polémica en términos distintos a los de 1894 , poniendo especial énfasis en el aspecto del lenguaje.

El 10 de abril de 1896, con el expresivo seudónimo de Armando Camorra se publica en La Prensa Libre un artículo titulado "Nuestros Taboadas", en el que se califica a los cuentos de Magón de "engendros lisiados de estos conchos de nuestra enteca literatura" (26). Magón contesta el 12 de abril en La Patria, con el artículo parodia "Cuentos opalinos":

"Equivocado andábame yo en la creencia de que lo natural, lo liso, lo exento de palabras rimbombantes y altisonantes y rebuscadas frases, era lo más aceptable en esta clase de composiciones, en ese género de costumbres entre cuyos vericuetos y zarzales metíme, por mal de mis pecados, sin consultar tus indiscutibles ingenios (...). Enderezo, pues, mi mal trazado surco y vuelvo a levantar mis terroncitos de escritor de costumbres en el estilo que tú cultivarias si de semejante pequeñez te ocuparas (...).

La desposada glauca luna con su gorro sarcástico de opalino corno, lenta surcaba las agonizantes ondas cortíneas del cerúleo éter esférico boca abajo... Retemblaba el opaco suelo bajo el torcido casco de un pollino renqui-pasitrotero con la desgarrada posta sangriento-glauca. Levantó al fresco ambiente su clarín guerrero, lanzó vendaval atronador de sus escuálidos lóbulos hinchando los enroscados anillos del gargüero y rebuznó (...). Matarredondeándose potrero de Pavas, hundióse en el perlífero nicoyano seno la desposada glauca luna con su gorro sarcástico de opalino corno (27).

Como se puede notar, la parodia de Magón tiende justamente a poner de relieve el efecto ridículo y grotesco que resulta al aplicar el estilo artificial y rebuscado de los "europeístas", a la descripción de la realidad criolla; Magón insiste en la necesidad de utilizar para este fin el "género de costumbres", con un estilo "natural" y "liso", y un lenguaje exento de palabras altisonantes $y$ frases rebuscadas.

\section{La "Magna Carta"}

En marzo de 1900 la aparición de El Moto de García Monge sucitó la publicación de una carta entusiasta dirigida a su autor por Magón, en la que éste hacía referencia a las antiguas manifestaciones de desagrado de Fernández Guardia ante las indias de Pacaca (28). Renace entonces con nuevos bríos la vieja polémica literaria, que se prolonga hasta noviembre de ese mismo año.

Fernández Guardia contestó a Magón con una carta fechada en París - en donde desempeñaba a la sazón funciones diplomáticas- publicada en La República el 24 de mayo de 1900. En esa carta afirma en un principio no haber querido decir lo que dijo en 1894, para terminar al final en cierta forma reafirmándolo (29). Sostiene Fernández Guardia en su carta que lo que él había defendido en 1894 era la libertad del escritor: 
"Se me acusa de patrocinar la teoría de que no se pueden tratar asuntos nacionales en forma literaria, o si se quiere, de ser adversario de lo que en ocasión anterior llamé nacionalismo en literatura. En honor a la verdad debo decir que jamás he pensado semejante cosa ni escrito nada que se le parezca; antes bien, recuerdo que lejos de condenar mi carta ningún género literario, fue como un alegato en defensa de la libertad del escritor (...). La libertad de inspiración del artista debe ser absoluta y... cada cual debe ir a buscarla donde la pueda encontrar" (30).

Lo que da calidad artística a un determinado material es, según Fernández, "el temperamento" del escritor. "Sostener que en las gentes y cosas de nuestro país no puede haber motivos de inspiración para el escritor y el artista es un absurdo. Todo, aunque no en grado igual, puede ser una sensación de arte... pero no es menos descabellado pretender que pueda existir algo que deba inspirar por fuerza a todos (...). El artista vive dominado por su temperamento... no puede divorciarse de su temperamento... Así vemos que de lo que el uno hace un portento, otro, con igual ingenio, sólo podrá sacar una obra mediocre, sin más causa que la diferencia de temperamento de ambos" (31).

Sin embargo, a pesar de esa aparente concesión magnánima al nacionalismo literario, con base en la libertad y el temperamento del escritor, no deja Fernández Guardia de referirse en términos altamente despectivos al "horrible guisote" de los que pretenden cultivar lo que él llama "el género Concho, de que el señor González se proclama con legítimo orgullo el fundador". Afirma que es "insensato exigir al novelista que se inspira únicamente en las pachotadas de nuestros campesinos..."; y aunque declara ser "el primero en aplaudir el esfuerzo de los que tratan de crear una literatura nacional", y admirar "muy de veras a los que encuentran muchas cosas que decir de una india de Pacaca", refuerza su vieja afirmación de que "ya sea por temperamento, mal gusto inveterado o perversidad natural, siempre he de hallar más interesante una parisiense o una de nuestras saladas josefinas, que la más apetitosa de esas robustas indígenas que, según veo, llegarán pronto a ser tan poéticas, como fama han tenido hasta aqui de buenas nodrizas, o chichiguas, como diría un nacionalista" (32). Finalmente afirma:

"A mi modo de ver el peligro no está en que nuestros jó-
venes escritores se arriesguen a explorar los jardines in-
mensos del ensueño y de la fantasía, siempre que de allí
vuelvan con hermosos ramilletes. Lo que no se debe su-
frir es esa plaga de escribidores que sin saber una palabra
de nada, sin tener talento, ni siquiera nociones elemen-
tales de gramática, se lanzan con admirable desfachatez a publicar las sandeces más enormes en un idioma que lo mismo puede ser castellano que guatuso" (33).

Esta última afirmación viene a reforzar nuestras reflexiones anteriores. Gagini y Fernández Guardia coinciden en 1894 -a pesar de sus discrepancias en cuanto al tema y los asuntos- en lo referente a la forma y el lenguaje apropiados para que una obra adquiera status literario; pero en esta nueva fase de la polémica, Fernández Guardia pareciera acercarse a la posición original de Gagini en 1894. Así se explica la aparente contradicción entre sus afirmaciones sobre la libertad del escritor para tratar "asuntos nacionales en forma literaria", por un lado; y sus diatribas, por otro lado, contra la "plaga de escribidores" que "sin nociones de gramática" cultivan el "género Concho", y escriben "las sandeces más enormes en un idioma que lo mismo puede ser castellano que guatuso".

Fernández Guardia pareciera mirar en 1900 con mayor benevolencia que en 1894 , la posibilidad de que se traten asuntos nacionales -lo que se verá confirmado por la publicación de Cuentos ticos al año siguiente y Magdalena en 1902-pero siempre que se respete la forma literaria, siempre que se utilice el castellano normal y el Diccionario de la Lengua Española (34); y no se recurra al guatuso, a las pachotadas o las sandeces populares y campesinas, como lo hacían los cultivadores del "género Concho". Estos últimos quedaban para Fernández Guardia al margen de lo literario, al transgredir los cánones académicos sobre la forma, el lenguaje y el género literarios (35).

Tres meses después, el 2 de setiembre de 1900, El Heraldo de Costa Rica reproduce la carta de Fernández Guardia - denominada por el redactor la "Magna carta" de la libertad literaria- acompañada de una introducción anónima, en donde se expresan algunos conceptos que vienen a confirmar cuáles eran las dos vertientes - "fondo y formma", "temas y lenguaje"- por las que corría entonces la polémica.

\footnotetext{
"Dos tendencias principales las distinguen, una de fondo $y$ otra de forma. Opinan los nacionalistas que los temas propios para las plumas de nuestros escritores deben ser genuinamente costarricenses y que debe tratarse en lo que a lengua se refiere en el español convencional que aquí priva (...). Un nacionalista, además, dejará a un lado el Diccionario de la Academia Española, que es bueno para el resto de los mortales que vegetamos en Hispano América, y se servirá únicamente del Diccionario de los Barbarismos costarricenses de don Carlos Gagini, como lo hizo ya el autor del "Moto" " (36).
} 


\section{El "Olimpo Literario": aristocracia y plebe.}

Pero este texto introduce además un nuevo factor digno de nuestro interés y consideración. Ya los formalistas rusos en sus reflexiones habían señalado la posibilidad de relacionar los fenómenos de la "hibridez" literaria y de la "canonización de los géneros inferiores", con los procesos de cambio social del período histórico en cuestión. Tomashevski indica que es posible establecer un "paraleIo" entre el proceso de surgimiento, transformación y "democratización" de los géneros literarios, y la progresiva "democratización" histórica de las relaciones entre las clases sociales (37). Algunas ideas expresadas en ese artículo anónimo, y las reacciones y comentarios que sucitaron posteriormente entre los polemistas, permiten adscribir un significado semejante al surgimiento de nuestro nacionalismo literario; permiten establecer una analogía entre las posiciones o escuelas literarias opuestas y la filiación político-social de sus defensores y cultivadores. Aseguraba el anónimo editor de la "Magna carta":

"En literatura como en política la simpatía de ideas y la analogía de temperamentos dan origen a las agrupaciones que se ha convenido en llamar escuelas o partidos. Algunos creemos que en San José, no contentos con las mil subdivisiones que tenemos al tratar de la cosa pública, se han creado también dos sectas literarias opuestas e irreconciliables. Llamemos a una liberal y a la otra nacionalista" (38).

A continuación afirma el redactor que el "círculo" liberal podría ser llamado "Olimpo literario" (39). El término Olimpo, como es bien sabido, tenía en esta época cierta connotación político-social; hacía referencia a la élite de intelectuales y políticos pertenecientes a la oligarquía cafetalera, que habían surgido a la vida pública con las reformas liberales, hacia 1889 . Por otra parte, ni Magón, ni Aquileo, habían ocultado nunca su simpatía política por el liberalismo; de manera que la oposición liberal/nacionalista apuntaba más bien hacia una diferenciación político-social, más que estrictamente político-doctrinaria. La oposición en definitiva se orientaba a señalar la pertenencia a la aristocracia oligárquica de los partidarios del academicismo cosmopolita, y el carácter más "plebeyo", de extracción popular o de "pobres de levita" (para usar una expresión de ...Magón (40) ) de los cultivadores y simpatizantes del "género concho".

Así lo comprendió Leonidas Briceño, en una respuesta al anónimo admirador de Fernández
Guardia, publicada dos días después de reimpresa la "Magna carta":

"...ellos por sí y ante sí (y sin poner sus firmas se entiende), han hecho dos agrupaciones del gremio literario, dos sectas irreconciliables, como ellos dicen, y han llamado a la una liberal y a la otra nacionalista: aristocracia y plebe, se comprende (...). A veces... dicen con desdén "que no quieren descender hasta uno". Bien, llegará el día en que los hagamos descender" (41).

De manera implícita Fernández Guardia parece aceptar también esta interpretación, al hacer una irónica referencia al origen "guanacasteco" de Briceño, como una explicación de su interés por el nacionalismo literario (42); además de sus reiteradas afirmaciones sobre la escasa "poesía" de nuestras "apetitosas y robustas indígenas", buenas sólo para nodrizas o "chichiguas", y de las "pachotadas" de nuestro pueblo, "sandio y sin gracia alguna".

No es difícil establecer, entonces, un paralelo entre el "Olimpo" literario de los academicistas y europeístas, que mantienen una posición tradicionalista, aristocrática y conservadora, en la temática, los recursos y el lenguaje; y la posición político-social de sus cultivadores, pertenecientes al "Olimpo" político y a la rancia aristocracia oligárquica. Manuel Argüello Mora, Ricardo Fernández Guardia, Manuel de Jesús Jiménez Oreamuno, Alejandro Alvarado Quirós, tenían todos relaciones muy estrechas de parentezco con los gobernantes de la época y tuvieron, además, destacada participación en la vida social y política del país (43). La mayoría de ellos, sin embargo -con excepción de Alvarado Quirós- transigieron con ciertos aspectos del nacionalismo literario, y cultivaron principalmente la crónica histórica. Pero la crónica histórica, precisamente, representa, dentro de las corrientes nacionalistas, la más aristocrática y conservadora, tanto por su temática referida al pasado histórico y a personajes de alto rango social, como por su estilo y lenguaje, académico, sobrio y con cierto sabor arcaico.

La procedencia social de los cultivadores y defensores del costumbrismo o "género concho" -Magón, Aquileo Echeverría, García Monge, Leonidas Briceño-, por otra parte, coincide con la visión de la realidad, más popular y "plebeya", que expresa esta corriente. Lo cual es notorio, tanto en los temas y personajes: hombres y escenas de la vida cotidiana campesina y popular; como en el tono natural y espontáneo, un lenguaje vernáculo y abigarrado, que intenta expresar la letra y el espíritu del habla y la idiosincracia de nuestro pueblo. 


\section{CONCLUSIONES}

En resumen, el análisis de las ideas expresadas por los participantes en la polémica sobre nacionalismo literario nos lleva a las siguientes conclusiones:

1) En un principio la polémica se planteó alrededor de los "asuntos" y los temas, que podían ser tratados por una literatura nacional, sin referencia a los aspectos formales y de lenguaje.

2) A pesar de sostener posiciones aparentemente opuestas, en cuanto a los temas que podía o debía tratar la literatura, Carlos Gagini y Ricardo Fernández Guardia partían, en los inicios de la polémica, de un concepto semejante, académico y canónico de la literatura, concepto que se ve corroborado por su práctica literaria (Hojarasca y Chamarasca). Ambos aceptaban como válidas únicamente las reglas y convenciones tradicionales europea, francesas y españolas, sobre el género, la forma y el lenguaje literarios.

3) Con el surgimiento del "costumbrismo" literario o "género concho" y más tarde de la crónica histórica, se intenta subsanar las limitaciones del academicismo europeísta. Ambos géneros buscan, mediante la introducción de elementos marginales y extraliterarios dentro de la literatura "culta" y "artística", la creación de nuevos géneros criollos, aptos para ofrecer una auténtica imagen literaria de la realidad, la vida y el hombre costarricenses.

Con la aparición del costumbrismo literario, la polémica sobre nacionalismo se plantea sobre sus verdaderas y necesarias bases, al incluir, no sólo la introducción de una nueva

\section{NOTAS}

(1) Castro Rawson, M. El costumbrismo en Costa Rica, Lehmann, San José, 1971, p. 110.

(2) Ibid., p. 112

(3) Amer, "Hojarasca", en: Cuartillas, 28 de mayo de 1984. Reproducido en: Castro, op. cit., p. 321. temática, sino también aspectos formales de género y lenguaje.

4) Las opiniones expresadas por Fernández Guardia en 1900 parecen iniciar una evolución de este autor -corroborada por la publicación de Cuentos ticos en 1901 y Magdalena en 1902- hacia posiciones más cercanas al nacionalismo literario; en 1900, no obstante, sigue sin aceptar el "género concho" y el lenguaje popular, como manifestaciones auténticamente literarias.

5) Diversas apreciaciones sucitadas por la reimpresión de la "Magna carta" de Fernández Guardia en setiembre de 1900, permiten establecer un paralelo entre las posiciones literarias y la procedencia social de los autores. Los miembros del "Olimpo" literario, pertenecientes, como los del "Olimpo" político, a la rancia aristocracia cafetalera, defienden y cultivan una literatura más conservadora, de corte académico y/o europeísta (Ricardo Fernández Guardia, Manuel Argüello Mora, Manuel de Jesús Jiménez, Alejandro Alvarado).

Los partidarios y cultivadores del "género concho" son de origen más "plebeyo", procedentes de la oligarquía "de medio pelo", "pobres de levita" según la pintoresca expresión de Magón, o de estratos populares: Magón, Aquileo Echeverría, Joaquín García Monge.

La procedencia social de los autores se refleja, tanto en su concepto de literatura, como en la visión literaria de la realidad que expresan las dos principales corrientes literarias de la época: el costumbrismo y la crónica histórica.
(4) Fernández Guardia, R., "El nacionalismo en literatura", El Heraldo de Costa Rica, 24 de junio de 1994. Reproducido en Castro, op. cit., p. 326-327.

(5) Céspedes, Benjamín de, "El nacionalismo en literatura", El Heraldo de Costa Rica, 10 de julio de 1894. Reproducido en Castro, op. cit., p. 333-335. 
Respetamos la caprichosa transcripción de los nombres rusos - posiblemente calcada del francés- que utiliza el articulista para referirse a Turguéniev y (Saltikov-) Schedrín.

(6) Ibidem

(7) Bonilla, A., Historia de la literatura costarricense, Ed. Costa Rica, San José, 1967, p. 110.

(8) Chase, A., "Notas para una historia de la narrativa costarricense", en: Narrativa contemporánea de Costa Rica, t. I, Ministerio de Cultura, San José, 1975 , p. 24 . El subrayado es del original.

(9) Ver: Bonilla, op. cit., p. 141; Portuguez de Bolaños E., El cuento en Costa Rica, p. 32 y 114.

(10) Sobre esto ver: Lukács G., "Arte y verdad objetiva" en: Problemas del realismo, Fondo de Cultura Económica, México, 1966. Ver también mi artículo "Arte y realismo en el pensamiento de Georg Lukács" en: Revista de Filosofía de la Universidad de Costa Rica, No. 49-50, 1981.

(11) Briceño L., Carta a Rafael Machado, El Heraldo de Costa Rica, 4 de setiembre 1900.

(12) Ver, por ejemplo: Tomashevski B., Teoria Literatury (Poetica), Leningrado, 1925. p. 162-165; Tynianov Yu. N., "Literaturni fact" ("El hecho literario", 1924) y "O literaturnoi evoliutsii" ("Sobre la evolución literaria", 1927) en: Poetica/Istoria literatury/kinó, Academia de Ciencias de la URSS, Moscú, 1977; Vinogradov V. V., "Evoliutsia russkovo naturalisma" ("La evolución del naturalismo ruso", 1928) en: Poética russkoi literatury, Academia de Ciencias de la URSS, Moscú, 1976; Shklovski V., Tetivá (La cuerda del arco), Moscú, 1970; Bajtín M., Problemy poetiki Dostoyevskovo, 3 ed., Moscú, 1972, cap. IV, y "La palabra en la novela", en: Ciencias sociales, Academia de Ciencias de la URSS, No. 1, 1978, p. 166.

(13) Ver: Tomashevski, op. cit., p. 164.

(14) Ver: Tynianov, "Literaturni fact", op. cit., p. 255 y "O literaturnoi evoliutsii", op. cit., p. 270.

(15) Tynianov, op. cit., p. 257.

(16) Fernández Retamar R., "Algunos problemas teóricos de la literatura hispanoamericana", en: $P a$ ra una teoría de la literatura hispanoamericana y otras aproximaciones, Cuadernos Casa 16, La Habana, 1975, p. 72.

(17) Ibid., p. 73.

(18) Ibid., p. 76.

(19) Magón, Carta a Joaquín García Monge, $1^{\circ}$ de marzo de 1900. En: Cuentos de Magón, edición J. M. Arce, Colección "Selectio", Lehmann, San José, 1968, p. 315.
(20) Magón, Carta a J. M. Arce, abril 30 y $1^{\circ}$ de mayo de 1924, op. cit., p. 318. El subrayado es nuestro.

(21) Ver el estudio y antología de Margarita Castro R. ya citado: El costumbrismo en Costa Rica.

(22) Gagini C., Diccionario de costarriqueñismos, 3 ed. Ed. Costa Rica, San José, 1975 , p. 11. El subrayado es nuestro.

(23) Arce J. M., "Manuel González Zeledón (Magón)" en: Cuentos de Magón, p. XXII-XXIII.

(24) Briceño L., op. cit., El subrayado es nuestro.

(25) Arce, op. cit., p. XXVI.

(26) Ver: Cuentos de Magón, p. 327.

(27) Cuentos de Magón, p. 328-329.

(28) "Ya verán don Ricardo Fernández Guardia y los que con él opinan que no hay mucho que decir de una india de Pacaca, hoy que usted les ha mostrado tanta belleza, tanta gracia y tanta chispa en la hija de ñor Soledá...". La revista, 9 de marzo de 1900. En: Cuentos de Magón, p. 314-315.

(29) En este sentido tenía razón Leonidas Briceño al asegurar que: "La Magna carta como por allí ha llamado alguien a la de Fernández Guardia, es para mí una magna contradicción. Este señor empieza proclamando en ella la libertad en el arte y luego se torna regañón con los que con él no opinan". El Heraldo de Costa Rica, 4 de setiembre de 1900.

(30) Fernández Guardia R., "Nacionalismo literario" en: La República, 24 de mayo 1900.

(31) Ibidem.

(32) Ibidem. El subrayado es del original.

(33) Ibidem. Subrayado del original.

(34) Ver carta publicada en El Heraldo de Costa Rica el 27 de octubre de 1900.

(35) Al menos esta pareciera haber sido su posición en 1900. Es probable que con el tiempo cambiara, pues cuando publica en 1926 la segunda edición de Cuentos ticos, solicita un prólogo a García Monge, uno de los principales cultivadores del "género concho" en 1900. (Ver: J. García M., "Renglones preliminares para Cuentos Ticos", en: Ricardo Fernández Guardia, presentado por V. H. Fernández, Ministerio de Cultura, 1978, p. 45.

(36) El Heraldo de Costa Rica, 2 de setiembre de 1900.

(37) Tomaskevski, op. cit., p. 164.

(38) El Heraldo de Costa Rica, 2 de setiembre de 1900.

(39) Ibidem. 
(40) Ver Cuentos de Magón, p. 312.

(41) Briceño, op. cit., El subrayado es nuestro.

(42) Ver carta de Fernández Guardia publicada en El Figaro, 10 de noviembre de 1900.
(43) Sobre la importancia político-social de las relaciones genealógicas, ver: Stone S. La dinastía de los conquistadores, EDUCA, San José, 1975.

\section{BIBLIOGRAFIA}

Amer (Carlos Gagini), "Hojarasca", en Cuartillas, 28 mayo 1894.

Anónimo, "El nacionalismo literario", en El Heraldo de Costa Rica, 2 setiembre 1900.

Arce J. M. "Manuel González (Magón)", en Cuentos de Magón, Colección Selectio, Lehmann, San José, 1968.

Argüello Mora M., La trinchera y otras páginas históricas, Ed. Costa Rica, San José, 1975.

Bajtin M., Problemy poetiki Dostoyevskovo, 3 ed., Moscú, 1972.

"La palabra en la novela", en Ciencias Sociales, Academia de Ciencias de la URSS, No. 1, 1978, p. 60.

Bonilla A., Historia de la literatura costarricense, Ed. Costa Rica, San José, 1967.

Briceño L, Carta a Rafael Machado, El Heraldo de Costa Rica, 4 setiembre 1900.

Castro Rawson M., El costumbrismo en Costa Rica, 2 ed., Lehmann, San José, 1971.

Céspedes de, B., "El nacionalismo en literatura", El Heraldo de Costa Rica, $1^{\circ}$ de julio de 1894.

Chase A. "Notas para una historia de la narrativa contemporánea", en Narrativa contemporánea de Costa Rica, T. I, Ministerio de Cultura, San José, 1975.

Echeverría A. J., Concherias, romances, epigramas y otros poemas, Prólogo de Arturo Agüero Ch., Colección Selectio, San José, s.f.e.

Fernández Guardia R., "El nacionalismo en literatura", El Heraldo de Costa Rica, 24 junio 1894.
"Nacionalismo literario", La República, 24 mayo 1900.

"Nacionalismo literario", El Heraldo de Costa Rica, 27 octubre 1900.

"Nacionalismo literario", El Figaro, 10 noviembre 1900.

Los cuentos, (Hojarasca, Cuentos ticos, La miniatura) Lehmann, 1971.

Magdalena, Imprenta y librería española, San José, 1902.

Fernández V. H., Ricardo Fernández Guardia, Ministerio de Cultura, San José, 1978.

Fernández Retamar R., Para una teoría de la literatura hispanoamericana y otras aproximaciones, Cuadernos Casa 16, La Habana, 1975.

Gagini C. (Ver: AMER).

Chamarasca, Imprenta y libería española, San José, 1898.

Diccionario de costarriqueñismos, 3 ed., Ed. Costa Rica, San José, 1975.

García Monge J., Obras escogidas, EDUCA, San José, 1974.

González Zeledón M. (Magón), Cuentos de Magón, Edición de J. M. Arce, Colección Selectio, Lehmann, San José, 1968.

Jiménez M. de J., Noticias de antaño, Imprenta Nacional, San José, 1946.

Lukacs G., Problemas del realismo, Fondo de cultura económica, México, 1966. 
Portuguéz de Bolaños, E., El cuento en Costa Rica, Lehmann, San José, 1964.

Quesada A. "Arte y realismo en el pensamiento de Georg Lukacs", en Revista de Filosofía de la Universidad de Costa Rica, No. 49-50, 1981.

Shklovski V., Tetivá, Moscú, 1970.

Stone S., La dinastía de los conquistadores, EDUCA, San José, 1975.
Tomashevski B., Teoría literatury (Poetica), Leningrado, 1925.

Tynianov Yu. N., Poetica/lstoria literatury/kinó, Academia de Ciencias de la URSS, Moscú, 1977.

Vinogradov V. G., Poetica russkoi literatury, Academia de ciencias de la URSS, Moscú, 1976. 
